\title{
Pantallas partidas I Split screens
}

\author{
María Augusta Barreiro \\ Email: augustabarreiro@gmail.com
}

Recibido: 10 junio 2020

Evaluado: 12 julio 2020

Publicado: 10 noviembre 2020

\section{Resumen}

La pandemia de COVID 19, detectada y notificada oficialmente el 31 de diciembre de 2019 en la ciudad China de Wuhan, ha dejado a la fecha: 408.481 muertes y 7'174.925 de contagiados distribuidos en 188 países del mundo de los cuales los más afectados son: Estados Unidos, Reino Unido, China, España, Italia y Brasil, de acuerdo con los últimos datos de la Universidad Johns Hopkins (junio 2020). En el corto plazo, esta pandemia se ha convertido en la principal causa de muerte superando la malnutrición, los homicidios, el cáncer y otras enfermedades graves.

En este contexto, la mayoría de países declararon el estado de alerta sanitaria, siendo obligatorio el confiamiento. Durante los meses que duró el estado de aislamiento absoluto, la vieja técnica cinematográfica denominada split screen (pantalla partida), protagonizó una resurrección inesperada convirtiéndose en el vehículo que nos permitió comunicarnos pero también crear y consumir cultura.

La pantalla partida o "split screen", es sin lugar a dudas, uno de los protagonistas más destacados de la pandemia de corona virus que afrontó la humanidad a partir del 31 de diciembre de 2019, cuando se notificó de manera oficial la noticia de esta grave enfermedad desde la ciudad China de Wuhan. Casi tan antigua como el propio cine, la split screen se convirtió en la herramienta que nos permitió sentir la cercanía de nuestras familias, colegas de trabajo, compañeros de estudio y profesores. Nos permitió expresar nuestra solidaridad, apoyo y compañía en momentos tan complicados como los que vivimos durante el largo período de cuarentena al que estuvieron sometidos la mayoría de países en el mundo.

Palabras clave: Covid 19; ciudadanía; solidaridad; Barcelona; Bon Pastor; operación Mercedes; monumento 


\section{Abstract}

The COVID 19 pandemic, detected and officially notified on December 31, 2019 in the Chinese city of Wuhan, has left to date: 408,481 deaths and 7,174,925 infected distributed in 188 countries of the world, of which the most affected are : United States, United Kingdom, China, Spain, Italy and Brazil, according to the latest data from Johns Hopkins University (June 2020). In the short term, this pandemic has become the leading cause of death, surpassing malnutrition, homicides, cancer and other serious diseases.

In this context, the majority of countries declared a state of health alert, being mandatory. During the months that the state of absolute isolation lasted, the old cinematographic technique called split screen (split screen), starred in an unexpected resurrection, becoming the vehicle that allowed us to communicate but also to create and consume culture.

The split screen or "split screen" is undoubtedly one of the most prominent protagonists of the corona virus pandemic that humanity faced as of December 31, 2019, when the news of this was officially notified serious illness from the Chinese city of Wuhan. Almost as old as the cinema itself, the split screen became the tool that allowed us to feel the closeness of our families, work colleagues, fellow students and teachers. It allowed us to express our solidarity, support and company in moments as complicated as those we lived through during the long period of quarantine in hmost countries in the world.

Keywords: Covid 19; citizenship; solidarity; Barcelona; Bon Pastor; operation Mercedes; monument

\section{Resum}

La pandèmia de COVID 19, detectada i notificada oficialment al 31 de desembre de 2019 a la ciutat xinesa de Wuhan, ha deixat a la data: 408.481 morts i 7'174.925 de contagiats distribuïts en 188 països de el món dels quals els més afectats són : Estats Units, Regne Unit, Xina, Espanya, Itàlia i el Brasil, d’acord amb les últimes dades de la Universitat Johns Hopkins (juny 2020). En el curt termini, aquesta pandèmia s'ha convertit en la principal causa de mort superant la malnutrició, els homicidis, el càncer i altres malalties greus.

En aquest context, la majoria de països van declarar l'estat d'alerta sanitària, sent obligatori l'confiamiento. Durant els mesos que va durar l'estat d'aïllament absolut, la vella tècnica cinematogràfica anomenada split screen (pantalla partida), va protagonitzar una resurrecció inesperada convertint-se en el vehicle que ens va permetre comunicar-nos però també crear i consumir cultura.

La pantalla partida o "split screen", és sense cap dubte, un dels protagonistes més destacats de la pandèmia de corona virus que va afrontar la humanitat a partir de 31 de desembre de 2019, quan es va notificar de manera oficial la notícia d'aquesta greu malaltia des de la ciutat xinesa de Wuhan. Gairebé tan antiga com el mateix cinema, la split screen es va convertir en l'eina que ens va permetre sentir la proximitat de les nostres famílies, col-legues de treball, companys d'estudi i professors. Ens va permetre expressar la nostra solidaritat, suport i companyia en moments tan complicats com els que vivim durant el llarg període de quarantena a què van estar sotmesos la majoria de països en el món.

Paraules clau: Covid 19; ciutadania; solidaritat; Barcelona; Bon Pastor; operació Mercedes; monument 
Idea

El objetivo del monumento que se presenta a continuación, es rendirle un justo homenaje a la ciudadanía solidaria que, en el marco de estos momentos difíciles, ha tendido puentes de comunicación, acompañamiento, apoyo y difusión de todo tipo de conocimientos y saberes a través de pantallas partidas. La metáfora de estar juntos pero separados, y sentir que somos seres comunitarios, se ha sentido en estos días como nunca antes a pesar de no estar físicamente presentes.

A través de la pantalla partida, ha sido posible yuxtaponer tiempos y espacios distintos para acercar familias, amigos, profesionales, alumnos y profesores. De hecho, el proyecto que se presenta a continuación, es el resultado de varias sesiones de trabajo en pantalla partida en las que se han recogido y pulido ideas y propuestas por medio de clases virtuales.

Consciente de que todo cambio en la infraestructura de una ciudad es, en sí mismo un cambio social, porque aquello que construimos nos construye también a nosotros, propongo la creación de este monumento en el que fuera parte del polígono industrial del barrio Bon Pastor, un barrio cuyos orígenes en los años veinte nos remontan a un polígono de casas baratas que sufrió durante mucho tiempo el abandono institucional y el aislamiento físico y simbólico del centro de la ciudad de Barcelona, un barrio que ha sido escenario de varias luchas vecinales gracias a las cuales se ha conseguido una notable mejora en la calidad de vida y acceso a servicios básicos.

\section{Emplazamiento}

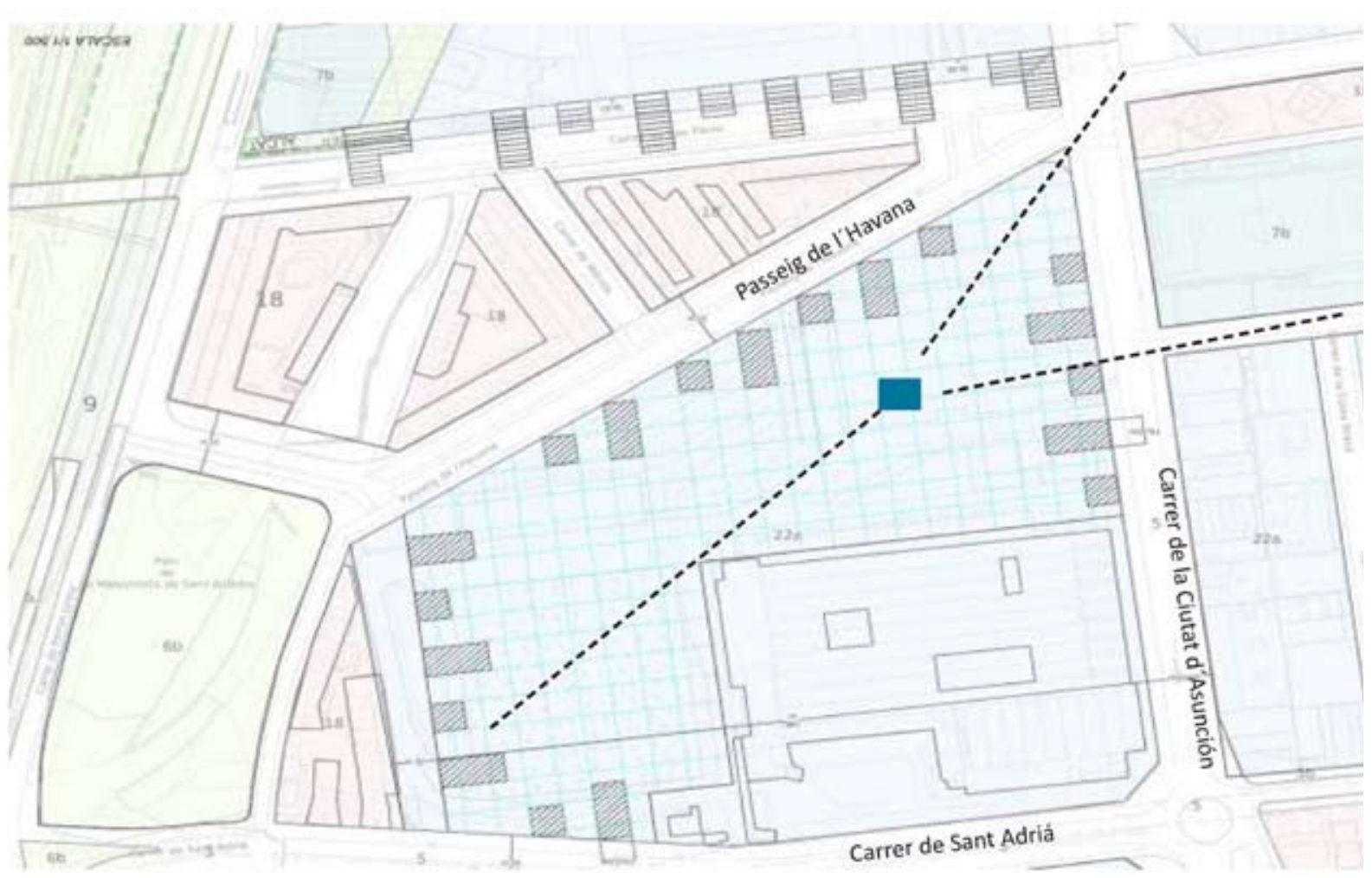




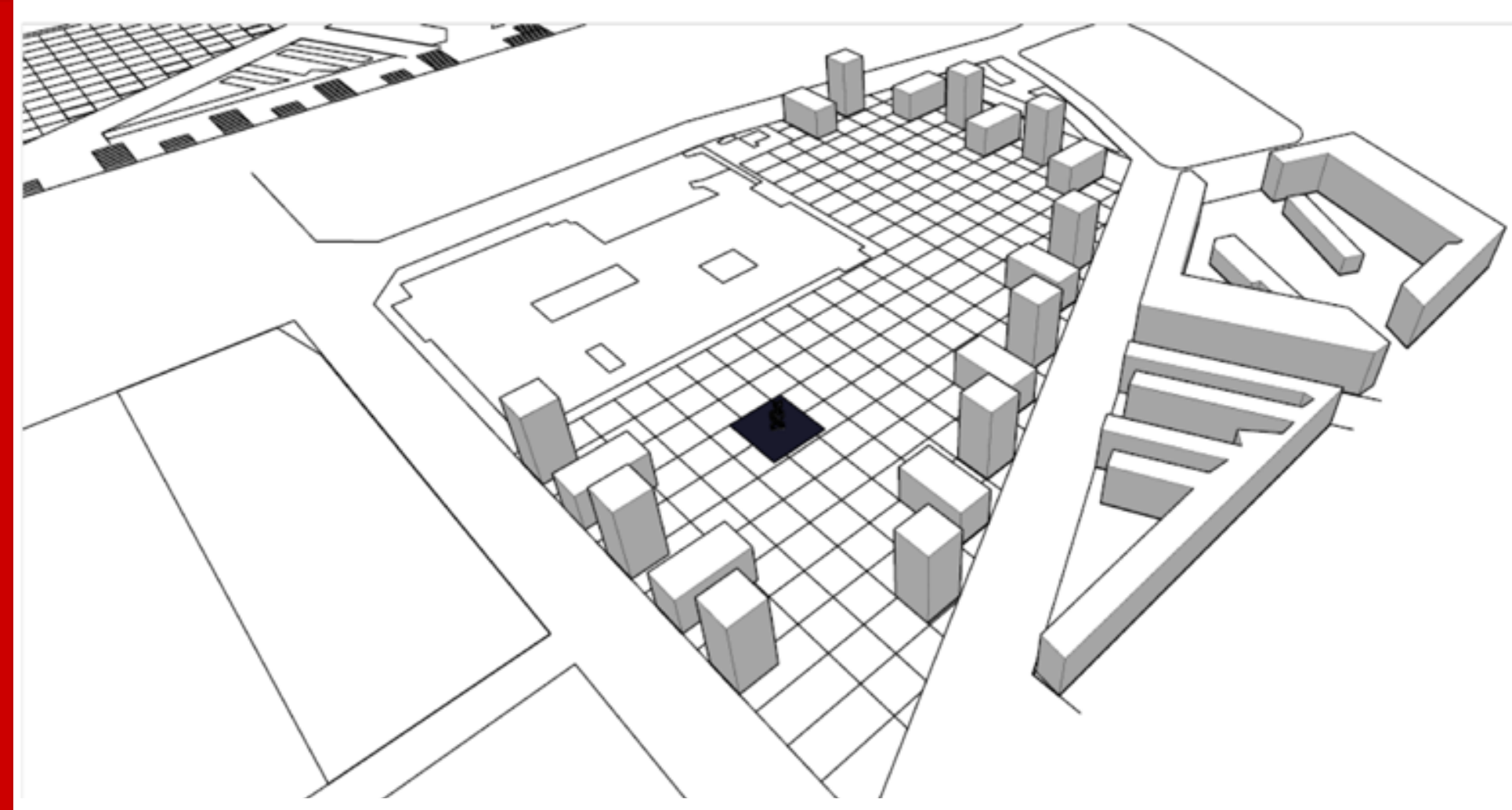

La trama base dibujada en la planta es de $15 \times 30$ m que es el doble de la estructura tipo para aparcamiento inferior que es de $7,7 \times 7,5 \mathrm{~m}$ entre ejes de pilares.

Los edificios están dimensionados según esta trama y hacen $15 \times 15 \mathrm{~m}$ los cuadrados y 15×50 m los rectangulares.

Tomando en cuenta estas dimensiones, se propone ubicar el monumento en un sitio visible desde todo el polígono, que no impida la libre circulación ni tampoco el aprovechamiento del espacio público, estratégicamente cerca de las acometidas eléctricas pero lo suficientemente lejos de los parqueaderos subterráneos

Evolución de la idea

\section{PROCESO DE DISEÑO}
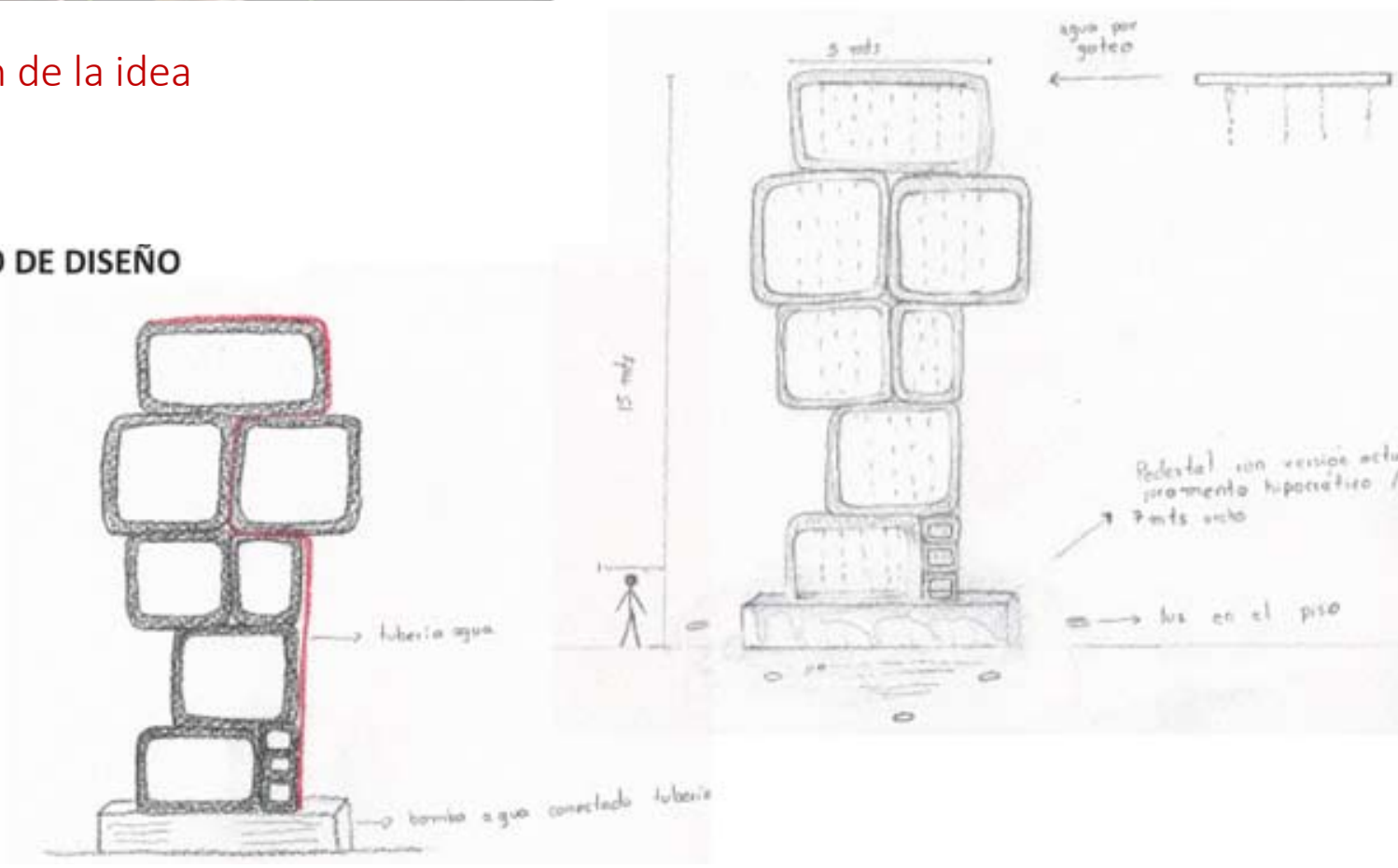


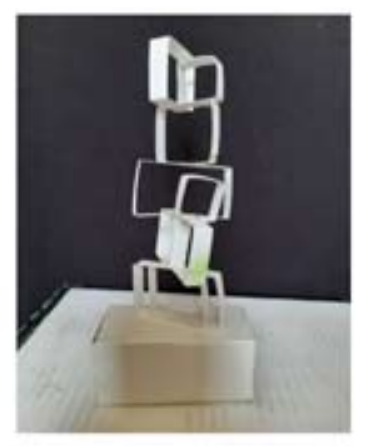

MODELO 2
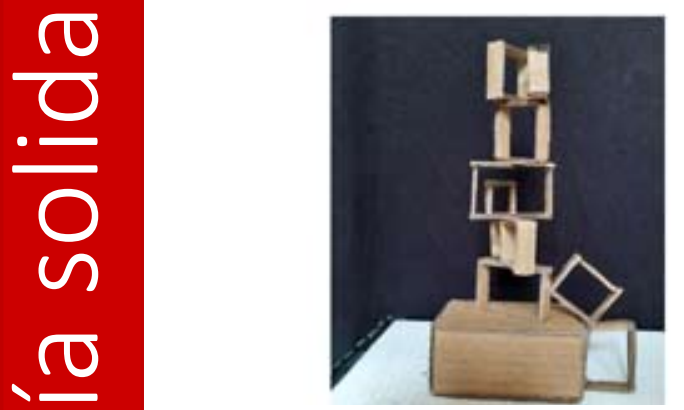

Propuesta definitiva



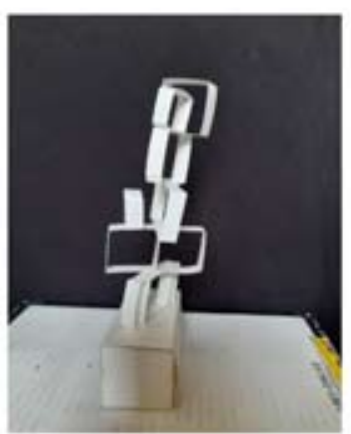

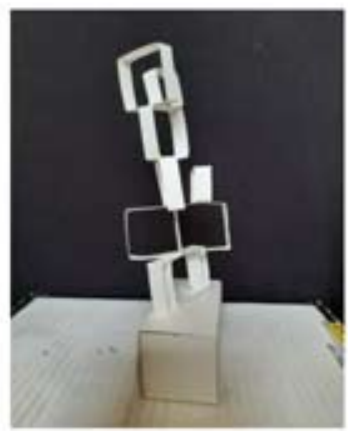

$\angle$ MODELO 1
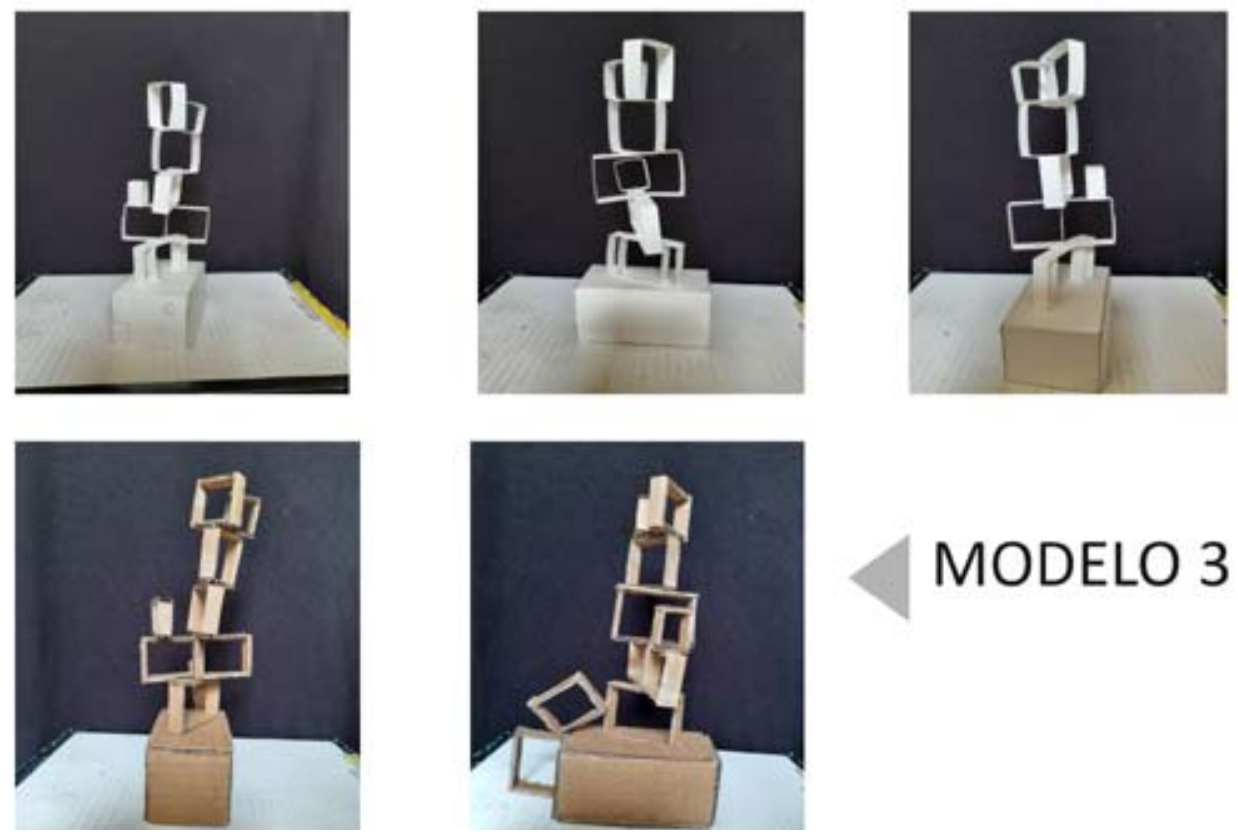
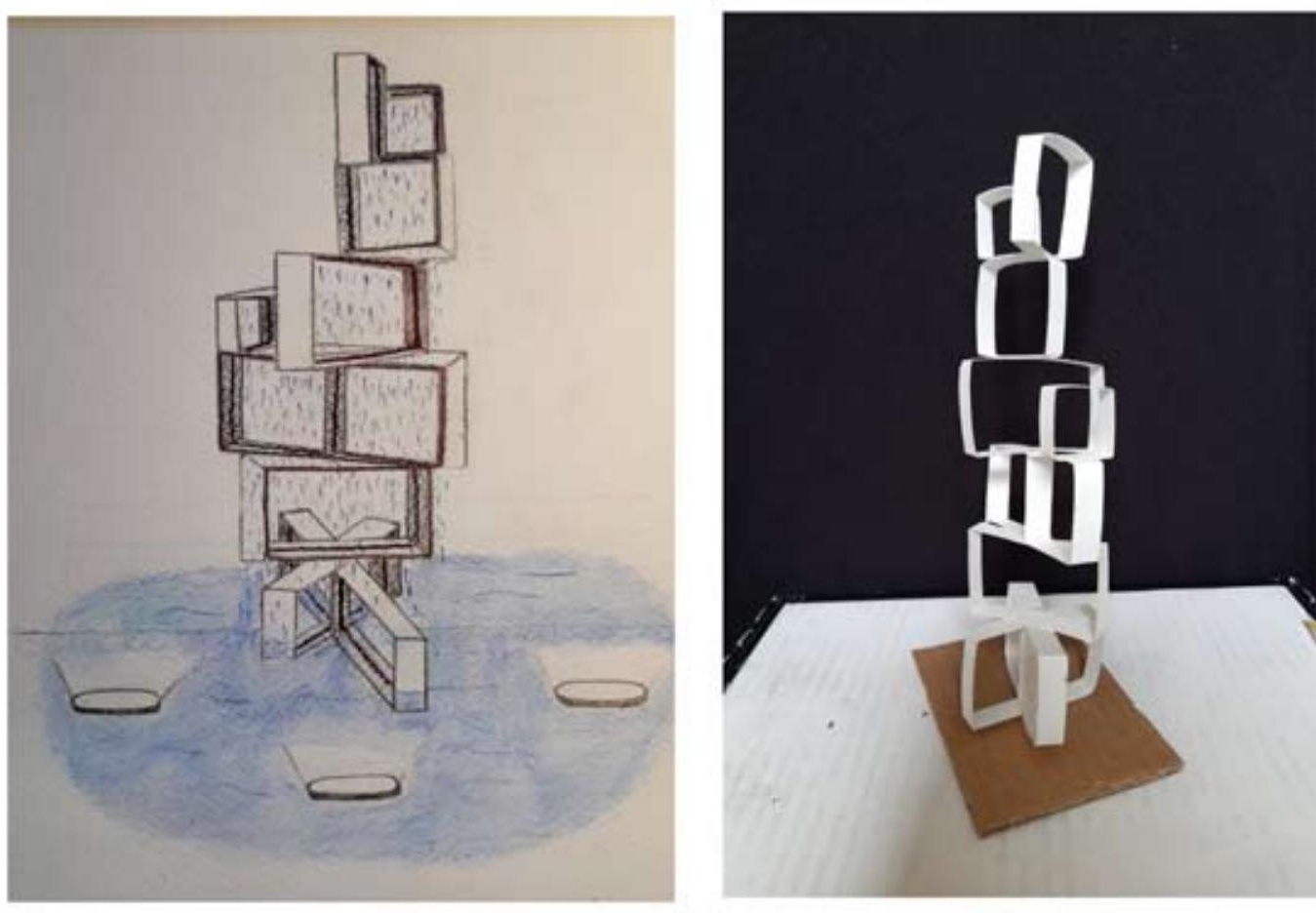

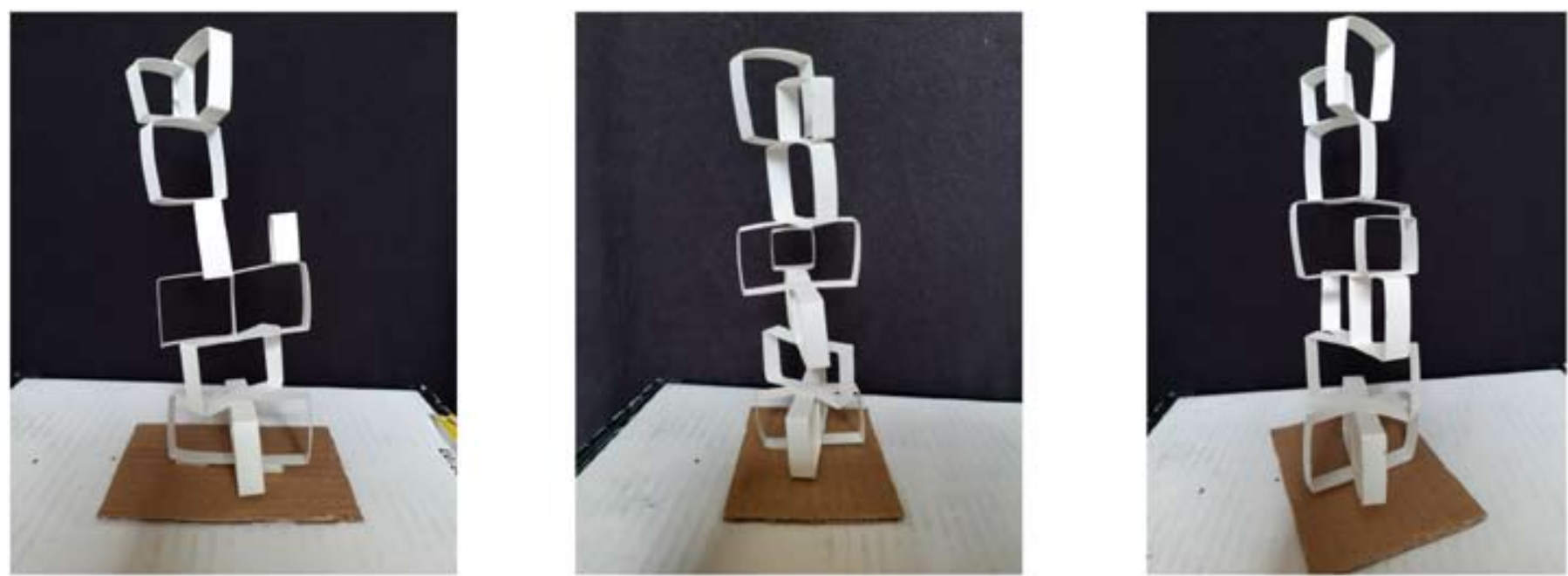

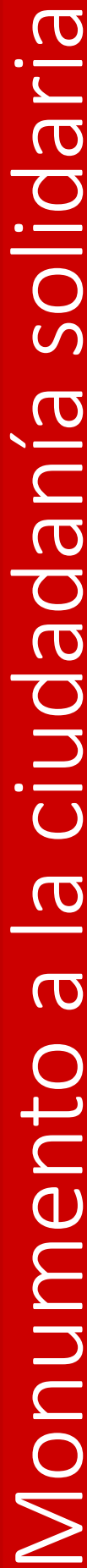
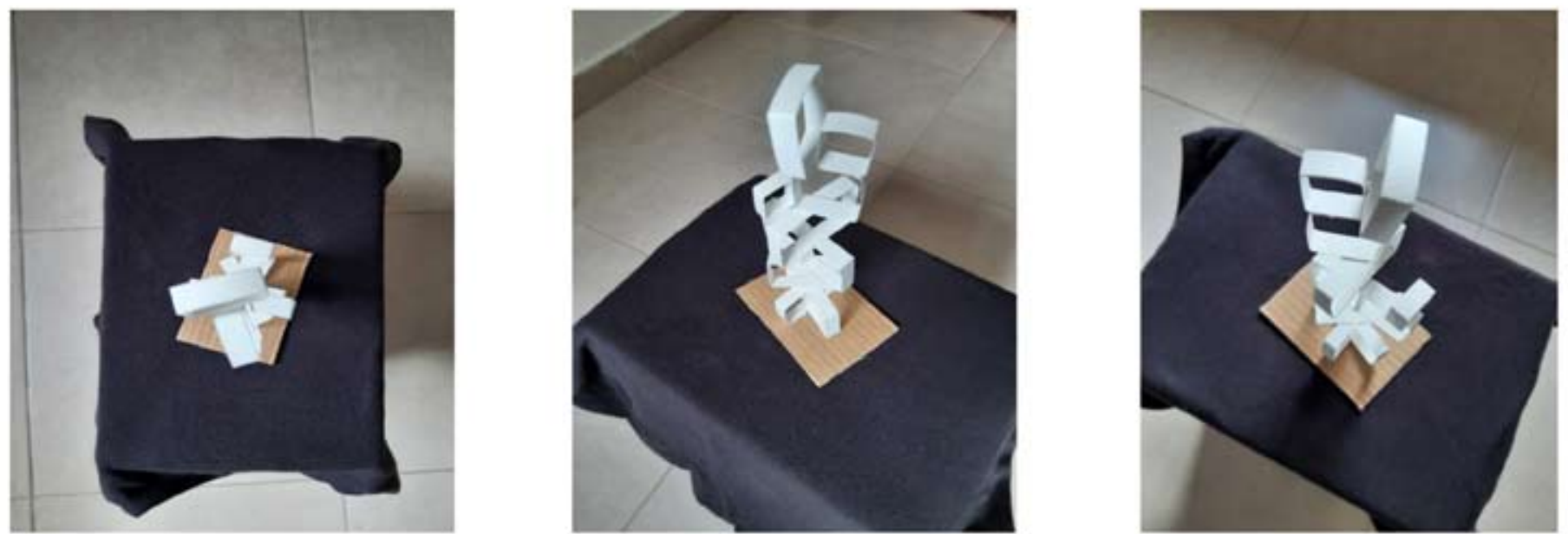

Secciones del Monumento

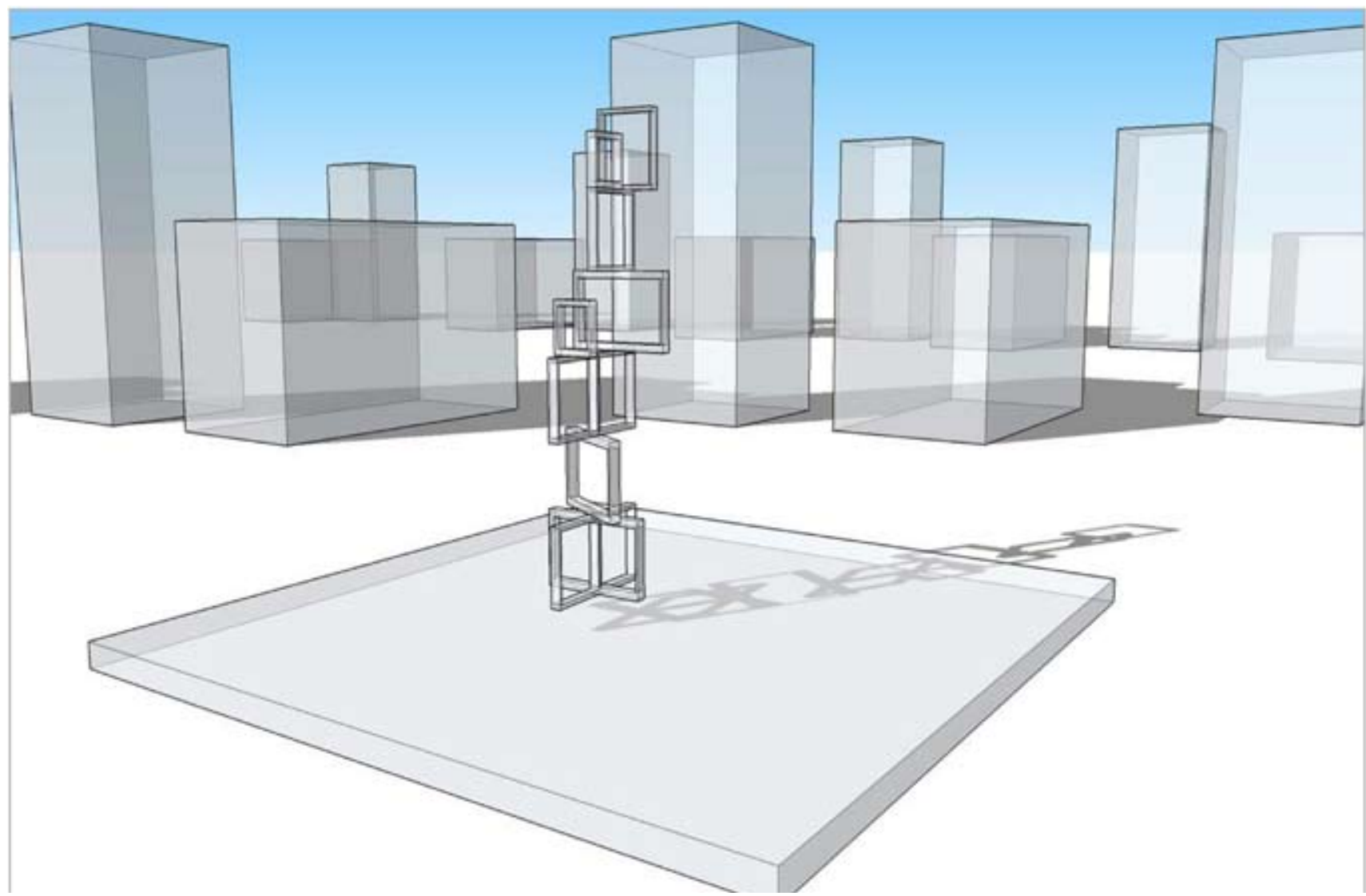



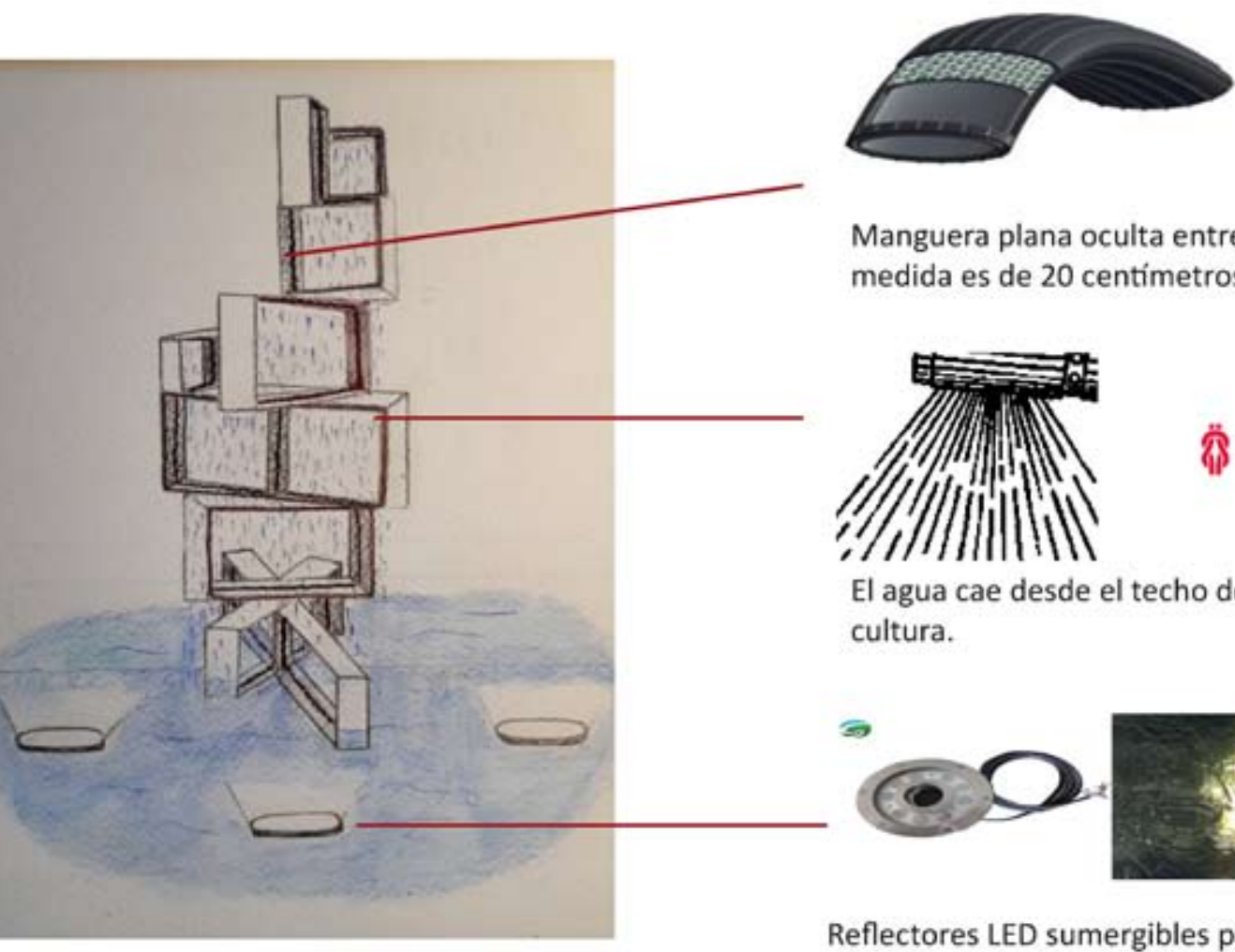

Manguera plana oculta entre el marco y el forro del marco cuya medida es de 20 centímetros de diámetro

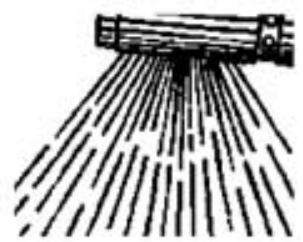

\section{芴 ESPIROFLEX}

El agua cae desde el techo de cada pantalla bañando toda la escultura.

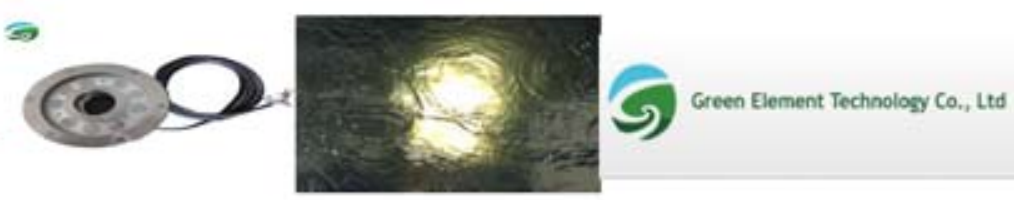

Reflectores LED sumergibles para fuentes

Anclajes y cimentación

El monumento mide $19 \mathrm{mts}$ de alto y está conformado por cuadrados y rectángulos superpuestos en diferentes ángulos de orientación que simulan diferentes tipos de pantallas.

Esta hecho de marcos de acero inoxidable cuya carga de peso se reparte equilibradamente al suelo a través de una caja de cimentación de hormigón armado y hierro que se encuentra a $1 \mathrm{mt}$ bajo el suelo.

Entre la pantallas o uniones hay soldaduras especiales que hacen que la estructura actúe monoliticamente. Como las pantallas son abiertas permiten la libre circulación del viento que suele ser el inconveniente de estructuras esbeltas. Su diseño permite resistir los esfuerzos tanto verticales como horizontales. Suelo de espejo de agua cóncavo.

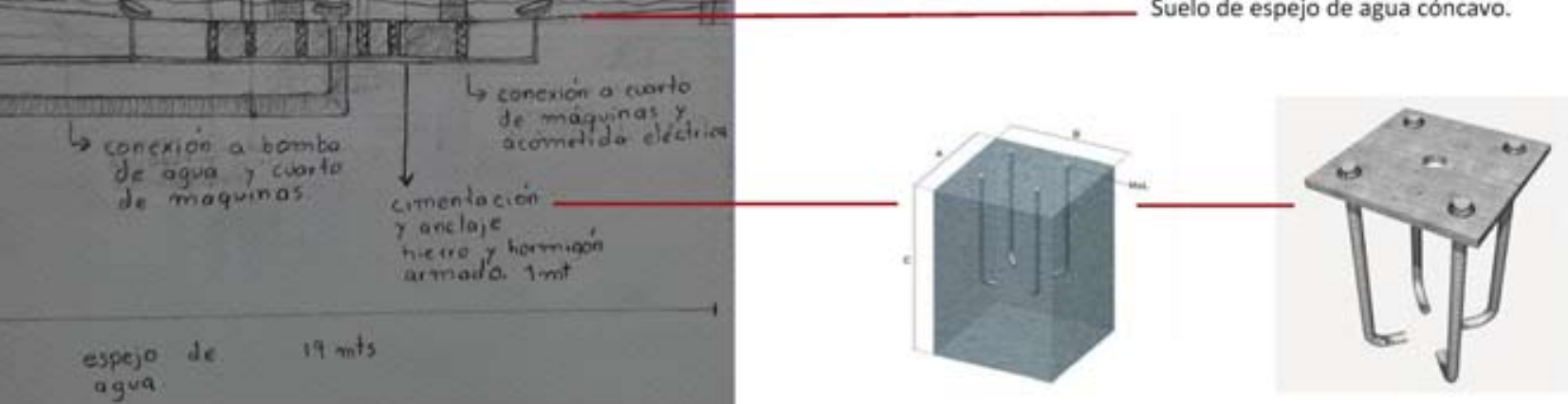

Placa de cimentación. 
Aproximación al mantenimiento
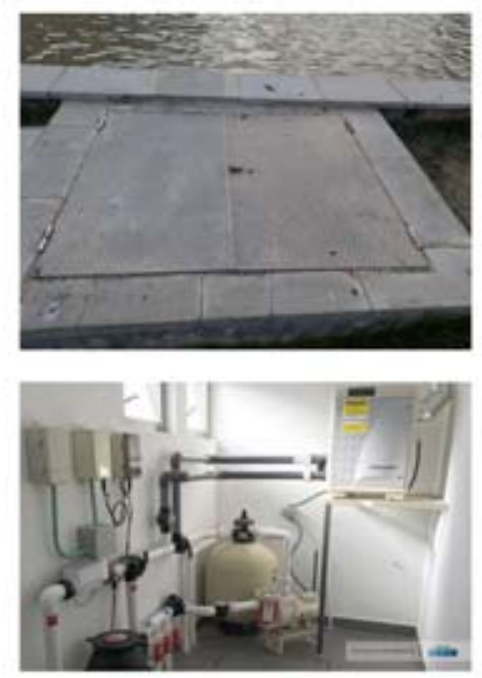

El mantenimiento se dará por medio de un cuarto de máquinas subterráneo al que se accede por unas puertillas de 70 $\mathrm{cm}$ de ancho aprox. En el cuarto estará ubicada la bomba de agua y las acometidas eléctricas para el funcionameinto de los reflectores.

Este cuarto estará ubicado a un metro de distancia del espejo de agua y conectado al sistema de alcantarillado y el sistema eléctrico.
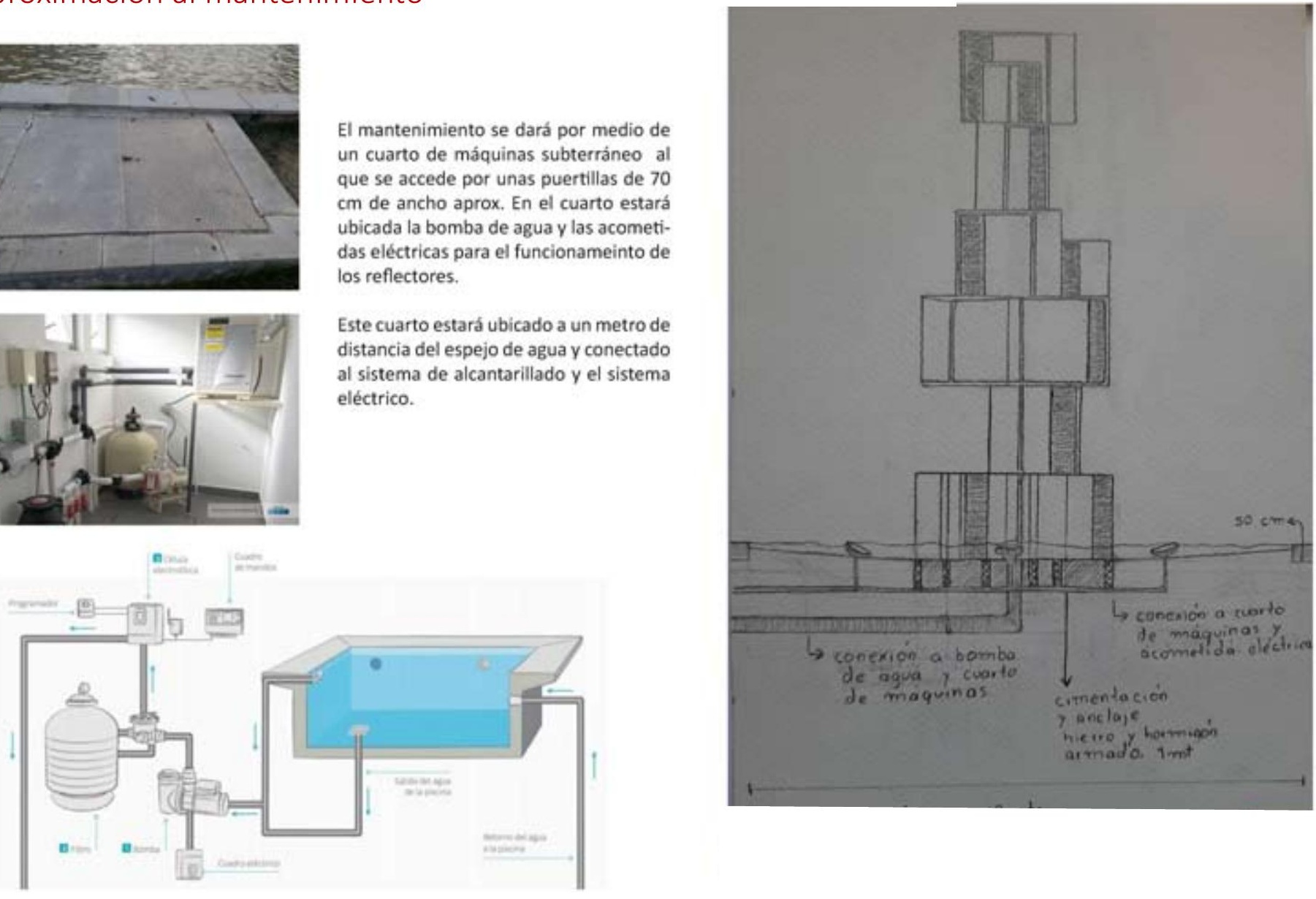

Renders

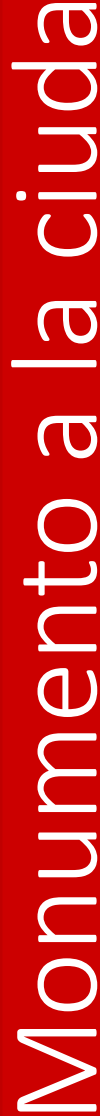


GENERALITAT DE CATALUNYA. (2004). Plan Urbanístico Sant Andreu- La Sagrera. Disponible en: http://ptop. gencat.cat/rpucportal/AppJava/cercaExpedient.do?reqCode=veureDocument\&codintExp=97810\&fromPa ge=load

GENERALITAT DE CATALUNYA. (2007). Plan de Mejora Urbana del Sector del En-torno de la Sagrera. Disponible en: http://ptop.gencat.cat/rpucportal/AppJa-va/cercaExpedient.do?reqCode=veureDocument\&co dintExp=239126\&from $\neg$ Page $=$ load

GENERALITAT DE CATALUNYA. (2014). Modificació puntual del Plan General Me-tropolitano en el subámbito 2 del sector IV, La Maquinista. Disponible en. http://ptop.gencat.cat/rpucportal/AppJava/cercaExpedient.do? reqCode $=-$ veureDocument\&codintExp $=268932 \&$ fromPage $=$ load

INSTITUTO MUNICIPAL DE HÁBITAT Y REHABILITACIÓN (2006). Remodelación del Bon Pastor. Disponible en: http://www.pmhb.org/document.asp?id=14\&su-bid=2

JOHN HOPKINS UNIVERSITY (06-2020). Coronavirus Resource Cen-ter. https://coronavirus.jhu.edu/map. html

VICENTE, ALEX. ( 9 de mayo de 2020). Pantalla partida: la metáfora visual de la pandemia. El País. Disponible enhttps://ja.cat/NhXCk

\section{AGRADECIMIENTOS}

La autora desea expresar su agradecimiento a la arquitecta Doménic Manciati por su inestimable ayuda en la realización de los renders de este trabajo. 